\title{
Up-regulation of divalent metal transporter 1 in 6-hydroxydopamine intoxication is IRE/IRP dependent
}

\author{
Hong Jiang ${ }^{1}$, Ning Song ${ }^{1}$, Huamin Xu ${ }^{1}$, Shuzhen Zhang ${ }^{1}$, Jun Wang ${ }^{1}$, Junxia Xie ${ }^{1}$ \\ ${ }^{I}$ Department of Physiology, Shandong Provincial Key Laboratory of Pathogenesis and Prevention of Neurological Disorders and \\ State Key Disciplines: Physiology, Medical College of Qingdao University, Qingdao 266071, China
}

Iron plays a key role in Parkinson's disease (PD). Increased iron content of the substantia nigra (SN) has been found in PD patients, and divalent metal transporter 1 (DMT1) has been shown to be up-regulated in the SN of both MPTP-induced PD models and PD patients. However, the mechanisms underlying DMT1 up-regulation are largely unknown. In the present study, we observed that in the SN of 6-hydroxydopamine (6-OHDA)-induced PD rats, DMT1 with the iron responsive element (IRE, DMT1+IRE), but not DMT1 without IRE (DMT1-IRE), was upregulated, suggesting that increased DMT1+IRE expression might account for nigral iron accumulation in PD rats. This possibility was further assessed in an in vitro study using 6-OHDA-treated and DMT1+IRE-over-expressing MES23.5 cells. In 6-OHDA-treated MES23.5 cells, increased iron regulatory protein (IRP) 1 and IRP2 expression was observed, while silencing of IRPs dramatically diminished 6-OHDA-induced DMT1+IRE up-regulation. Pretreatment with $\mathrm{N}$-acetyl-L-cysteine fully suppressed IRPs up-regulation by inhibition of 6-OHDA-induced oxidative stress. Increased DMT1+IRE expression resulted in increased iron influx by MES23.5 cells. Our data provide direct evidence that DMT1+IRE up-regulation can account for IRE/IRP-dependent 6-OHDA-induced iron accumulation initiated by 6-OHDA-induced intracellular oxidative stress and that increased levels of intracellular iron result in aggravated oxidative stress. The results of this study provide novel evidence supporting the use of anti-oxidants in the treatment of PD, with the goal of inhibiting iron accumulation by regulation of DMT1 expression.

Keywords: divalent metal transporter 1, iron, iron regulatory protein, Parkinson's disease, oxidative stress, antioxidant Cell Research (2010) 20:345-356. doi: 10.1038/cr.2010.20; published online 2 February 2010

\section{Introduction}

Recently, increasing evidence suggests that iron plays a key role in Parkinson's disease (PD). Increased iron content has been observed in the substantia nigra (SN) of

Correspondence: Hong Jiang ${ }^{\mathrm{a}}$, Junxia Xie ${ }^{\mathrm{b}}$

${ }^{a}$ Tel: +86-532-83780191; Fax: +86-532-83780136

E-mail: jhkyk@163.com

${ }^{\mathrm{b}}$ Tel: +86-532-85955891; Fax: +86-532-85953085

E-mail: jxiaxie@public.qd.sd.cn

Abbreviations: DFO (desferrioxamine mesylate); DMT1 (divalent metal transporter 1); HBS (HEPES-buffered saline); 6-OHDA (6-hydroxydopamine); IRE (iron response element); IRP (iron regulatory protein); $\Delta \Psi \mathrm{m}$ (mitochondrial transmembrane potential); NAC ( $N$-acetyl-L-cysteine); PD (Parkinson's disease); PBS (phosphate-buffered saline); ROS (reactive oxygen species); siRNA (small interfering RNA); SN (substantia nigra); TfR1 (transferrin receptor 1); UTR (untranslated region); MPTP (1-methyl-4phenyl-1,2,3,6-tetrahydropyridine); $\mathrm{MPP}^{+}$(1-methyl-4-phenylpyridinium) Received 18 June 2009; revised 24 August 2009; accepted 14 October 2009; published online 2 February 2010
PD patients, as well as in 6-hydroxydopamine (6-OHDA) and 1-methyl-4-phenyl-1,2,3,6-tetrahydropyridine (MPTP)-induced PD animal models [1-9]. A recent study showed that iron accumulates in individual dopaminergic neurons prior to their degeneration [10]. This finding supports the idea that iron accumulation is one of the primary events leading to the degeneration, if not the subsequent death, of dopaminergic neurons. However, the precise mechanism underlying abnormal iron accumulation in the dopaminergic neurons of the $\mathrm{SN}$ in $\mathrm{PD}$ has not been fully elucidated.

Divalent metal transporter 1 (DMT1), also known as natural resistance associated macrophage protein 2 (Nramp2), is a widely expressed transmembrane protein. Depending on the presence or absence of the iron response element (IRE) at its 3'-untranslated region (UTR), DMT1 mRNA encodes two proteins differing at their C-termini, DMT1 with IRE (+IRE) and DMT1 without IRE (-IRE). Until now, DMT1 is thought to be one of 
the endogenous transporters of ferrous iron. A more recent study revealed that DMT1 is up-regulated in the SN of both MPTP-induced PD models and PD patients [6], which is consistent with our previous findings that increased DMT1 expression accounts for the increased ferrous iron influx in 6-OHDA- and 1-methyl-4-phenylpyridinium $\left(\mathrm{MPP}^{+}\right)$-treated cells $[11,12]$. These findings suggest that DMT1 might at least partially account for the iron accumulation in the SN in PD. However, these studies provided no direct evidence as to the mechanisms underlying DMT1 up-regulation. In discussing the results, Salazar et al. [6] assumed that MPTP-associated inhibition of mitochondrial complex I resulted in increased levels of reactive oxygen and nitrogen species as well as ATP depletion, and that these two events could augment the binding activity of iron regulatory proteins (IRPs) controlling the expression of DMT1+IRE. In support of this hypothesis, the authors cited our recent finding that $\mathrm{MPP}^{+}$was sufficient to increase DMT1 expression and iron uptake in MES23.5 cells [12]. Both MPTP and 6-OHDA are classical neurotoxins for modeling PD; 6-OHDA induces specific damage via oxidative stress and MPTP is a mitochondrial complex I inhibitor. However, our data showed that $\mathrm{MPP}^{+}$-induced DMT1 up-regulation occurred in an IRE/IRP-independent manner. Therefore, it is worth clarifying whether IRE/IRP is involved in the observed 6-OHDA-induced DMT1 upregulation.

In the present study, we show that DMT1+IRE upregulation in 6-OHDA-induced PD models occurs in an IRE/IRP-dependent manner and that it is initiated by 6 -OHDA-induced intracellular oxidative stress. This effect could be fully abolished by treatment with the antioxidant $N$-acetyl-L-cysteine (NAC). We present direct evidence for the mechanisms underlying DMT1 up-regulation in PD. Our results tentatively support the
A

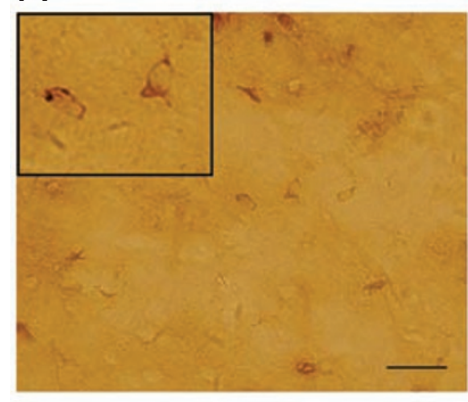

C

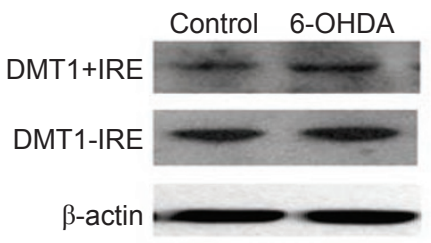

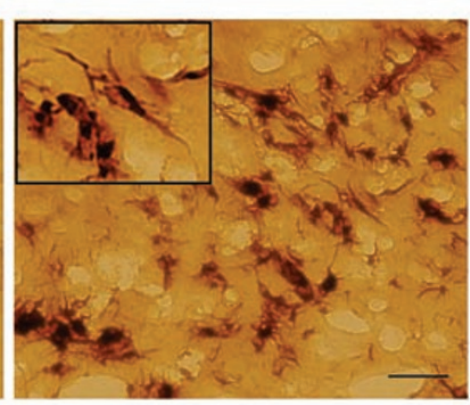

B

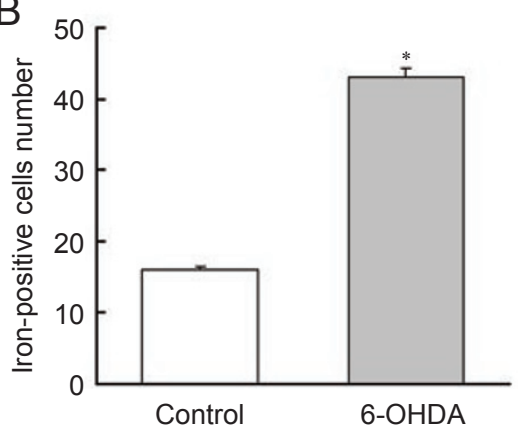

D

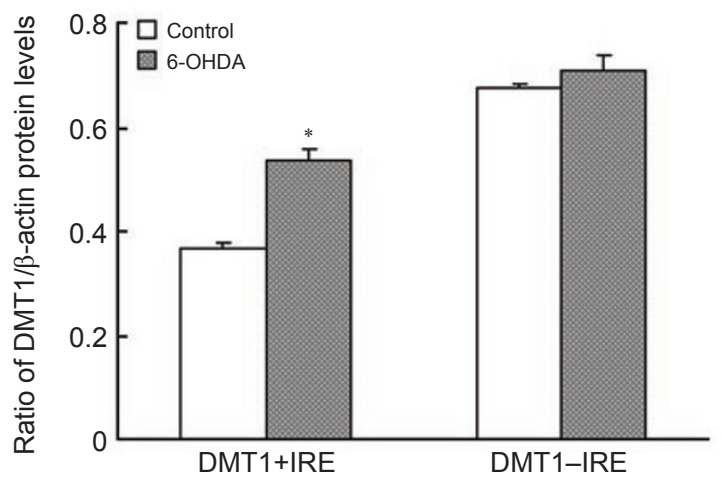

Figure 1 Iron content and DMT1 expression in the SN of normal and 6-OHDA lesioned rats. Both the number of iron-positive cells and the expression of DMT1+IRE were increased in the lesioned SN of 6-OHDA-induced PD rats. (A) Iron staining was applied to detect iron content. In the $\mathrm{SN}$ of the control group, there were a few small and round iron-positive cells. The number of iron-positive cells was significantly increased in the SN of 6-OHDA-lesioned rats. Scale bar $=50 \mu \mathrm{m}$. (B) Statistical analysis. Data are presented as the average number of positive cells in different fields. $* P<0.01$, compared with control. (C) Western blotting was applied to detect both forms of DMT1 expression. Increased expression of DMT1+IRE, rather than DMT1-IRE, was observed in 6-OHDA-lesioned rats. $\beta$-Actin was used as a loading control. (D) Statistical analysis. Data are presented as the ratio of DMT1+IRE or DMT1-IRE to $\beta$-actin. Each bar represents the mean \pm S.E.M. of six independent experiments. $* P<0.05$, compared with control. 
administration of antioxidants in the treatment of PD as a means of inhibiting iron accumulation through regulation of IRPs and DMT1 expression.

\section{Results}

The number of iron-positive cells in the $S N$ increased in 6-OHDA-induced $P D$ rats

Using Perl's iron staining, we observed iron-positive cells in the SN of 6-OHDA-induced PD rats and control animals. In the SN of control animals, there were a few iron-positive cells with small, round and glial-like morphologies. The number of iron-positive cells was significantly increased in the lesioned SN of 6-OHDA-induced $\mathrm{PD}$ rats (Figure 1A and $1 \mathrm{~B}$ ), indicating increased iron content in this region after 6-OHDA treatment.

DMT1+IRE, but not DMT1-IRE, expression was upregulated in vivo in the lesioned $S N$ of 6-OHDA-induced $P D$ rats

To determine the reason for the increased iron content in 6-OHDA-induced PD rats, we investigated changes in DMT1 \pm IRE expression in lesioned SN using western blotting and real-time PCR. The expression of DMT1+IRE mRNA and protein on the lesioned sides of 6-OHDA PD rats was increased significantly compared with that on the unlesioned sides and in the control. However, there were no changes observed in DMT1-IRE expression (Table 1; Figure 1C and 1D).

6-OHDA-induced up-regulation of DMT1+IRE, rather than DMT1-IRE, in vitro was responsible for increased iron influx in MES23.5 cells

We next examined the expression of DMT1 $1 \pm$ IRE in 6-OHDA-treated MES23.5 cells in vitro. To avoid the influence of cell loss, incubation with $10 \mu \mathrm{mol} / \mathrm{L}$ 6-OHDA for $24 \mathrm{~h}$ was employed. Similar to the results obtained in the in vivo experiments, DMT1+IRE, but not DMT1-IRE, was up-regulated both at the mRNA and at the protein levels in 6-OHDA-treated MES23.5 cells (Table 1; Figure 2A and 2B). No changes were observed

Table 1 Real-time PCR analysis of DMT1+/-IRE mRNA expression in 6-OHDA lesioned rats and 6-OHDA-treated MES23.5 cells

\begin{tabular}{lll}
\hline & DMT1+IRE & DMT1-IRE \\
\hline Rats & $2.314 \pm 0.04^{*}$ & $0.967 \pm 0.04$ \\
MES23.5 cells & $3.108 \pm 0.088^{\dagger}$ & $0.996 \pm 0.044$ \\
\hline
\end{tabular}

Data are presented as fold changes in mRNA expression with treatment vs control in rats and MES23.5 cells. $* P<0.01$, compared with normal rats (designated as 1 ). ${ }^{\dagger} P<0.01$, compared with MES23.5 cells without 6-OHDA treatment (designated as 1).
A

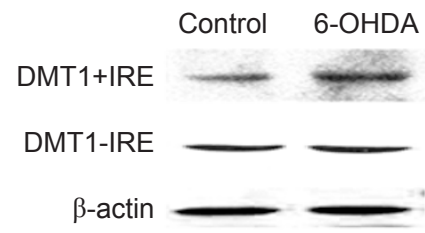

$\mathrm{B}$
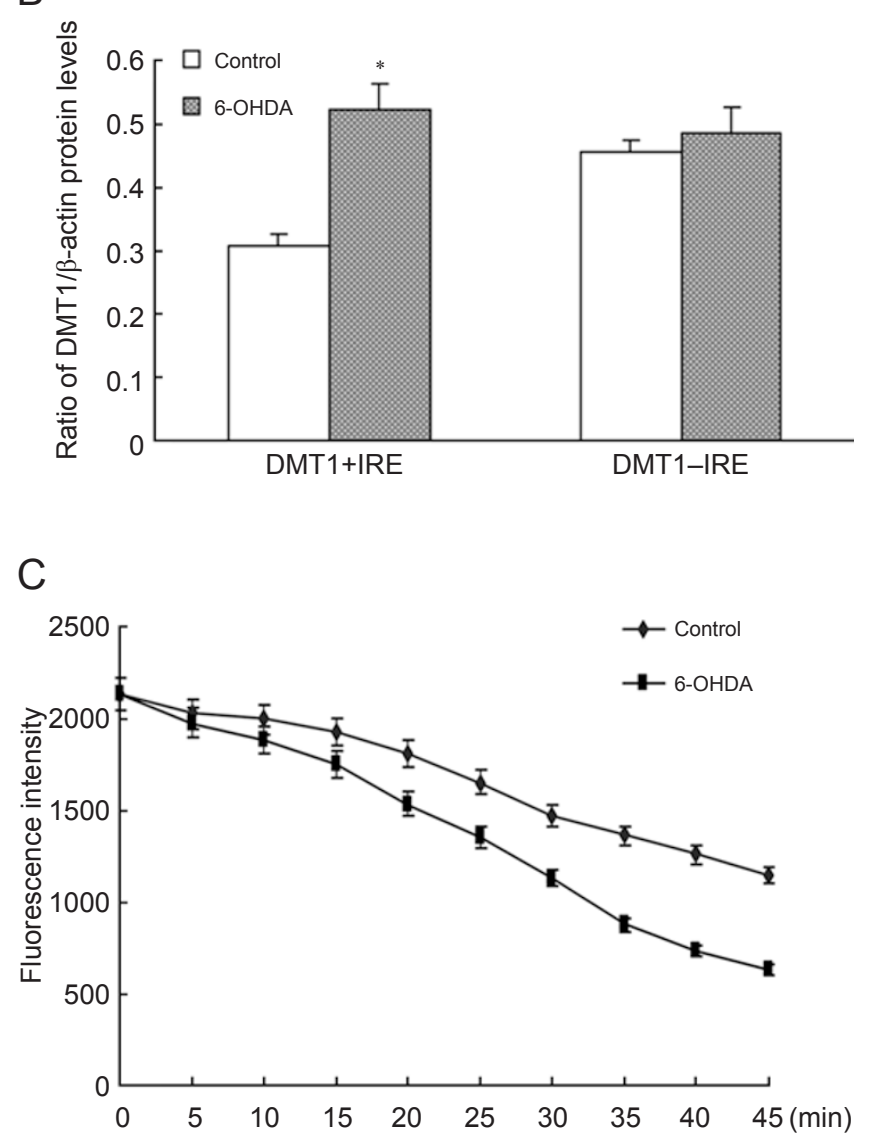

Figure 2 DMT1 expression and ferrous iron influx in MES23.5 cells with 6-OHDA treatment. 6-OHDA-induced DMT1+IRE upregulation and subsequent increased iron influx in MES23.5 cells. (A) Western blotting was applied to detect the expression of DMT1 1 IRE in MES23.5 cells. Increased expression of DMT1+IRE was observed in $10 \mu \mathrm{mol} / \mathrm{L}$ 6-OHDA-treated cells. $\beta$-Actin was used as a loading control. (B) Statistical analysis. Data are presented as the ratio of DMT1+IRE or DMT1-IRE to $\beta$-actin. Each bar represents the mean \pm S.E.M. of six independent experiments. $* P<0.05$, compared with control. (C) Ferrous iron influx into MES23.5 cells was determined by the quenching of calcein fluorescence, an indicator of intracellular iron level. The fluorescence intensity represents the mean value of 35-40 separate cells from four separate fields at each time point and is presented as the mean \pm S.D. of six independent experiments. When using $1 \mathrm{mmol} / \mathrm{L}$ ferrous iron to perfuse the cells, there was a more rapid decrease in fluorescence intensity in cells treated with $10 \mu \mathrm{mol} / \mathrm{L} 6-\mathrm{OHDA}$ compared with control cells, indicating increased ferrous iron influx in 6-OHDA-treated cells (two-way ANOVA, F = 22.068, $P<0.01$, compared with control). 
in cells that were only treated with the $2 \mu \mathrm{g} / \mathrm{mL}$ ascorbic acid solvent (data not shown). We also observed the ferrous iron influx process of these cells. When cells were perfused with $1 \mathrm{mmol} / \mathrm{L}$ ferrous iron, there was a significant decrease in the fluorescence intensity of 6-OHDAtreated cells compared with that of control cells (Figure $2 \mathrm{C}$ ), indicating that cells treated with 6-OHDA had increased ferrous iron uptake. To verify that this process is mediated by DMT1, we next examined whether over-expression of DMT1 in MES23.5 cells resulted in increased ferrous iron influx. We generated a stable cell line by transfection with pcDNA3.1-DMT1+IRE. In these cells, there was a 2.09-fold increase in the DMT1 protein level compared with cells transfected with pcDNA3.1 blank plasmid (Figure $3 \mathrm{~A}$ and $3 \mathrm{~B}$ ). When perfused with 1 $\mathrm{mmol} / \mathrm{L}$ ferrous iron, cells with DMT1+IRE over-expression showed a more rapid decrease in fluorescence intensity than control cells (Figure 3C). Taken together, these results indicate that 6-OHDA-induced up-regulation of DMT1+IRE in MES23.5 cells in vitro was responsible for increased iron influx.

Enhanced iron influx induced further reduction in mitochondrial transmembrane potential $(\triangle \Psi m)$ and reactive oxygen species (ROS) generation in MES23.5 cells with DMT1 over-expression

Increased expression of DMT1+IRE leads to increased intracellular iron content when the cells are incubated with iron. Iron, which is capable of catalyzing the production of $\mathrm{H}_{2} \mathrm{O}_{2}$ and forming highly reactive hydroxyl radicals that result in mitochondrial dysfunction and oxidative damage, plays a key role in oxidative stress. To evaluate intracellular oxidative stress, we measured $\Delta \Psi \mathrm{m}$ and ROS production. Transfection of cells with pcDNA3.1 or pcDNA3.1-DMT1+IRE had no effect on $\Delta \Psi \mathrm{m}$ and did not alter basal ROS production (data not shown). Most of the cells in the pcDNA3.1 group appeared in the high Rh123 fluorescence field, which is indicative of intact, viable cells with high $\Delta \Psi \mathrm{m}$. When these cells were treated with $100 \mu \mathrm{mol} / \mathrm{L}$ ferrous iron, there was a $15.32 \%$ reduction in Rh123-positive cells, indicating mitochondrial dysfunction. In cells of the pcDNA3.1-DMT1+IRE group, there was a significant $42.93 \%$ decrease in $\Delta \Psi \mathrm{m}$ with ferrous iron incubation (Figure 4A and 4C). Since $\triangle \Psi \mathrm{m}$ disruption is involved in ROS production, we also measured ROS production in cells with DMT1 overexpression and in control cells, using a fluorescencesensitive probe, carboxy- $\mathrm{H}_{2}$ DCFDA. MES23.5 cells over-expressing DMT1+IRE showed a significant $68 \%$ increase in ROS generation with ferrous iron incubation, while cells in the pcDNA3.1 group showed only a $26.12 \%$ increase (Figure $4 \mathrm{~B}$ and $4 \mathrm{D}$ ). This indicated
A

pcDNA3.1 pcDNA3.1-DMT1+IRE

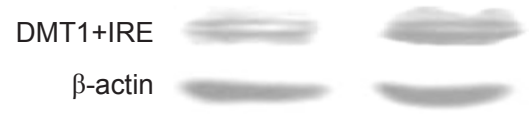

B

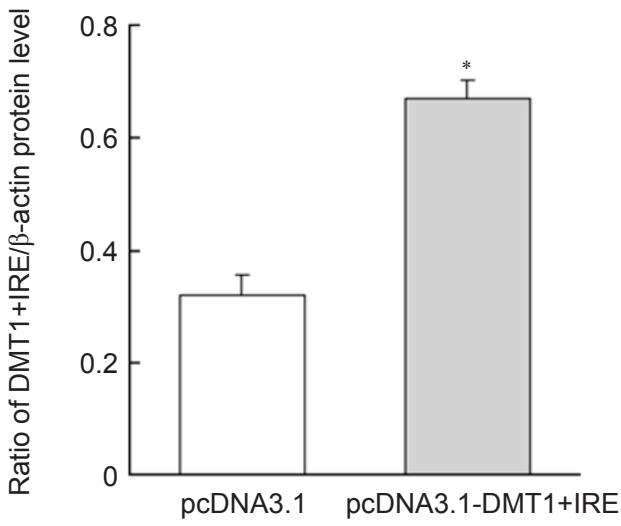

C

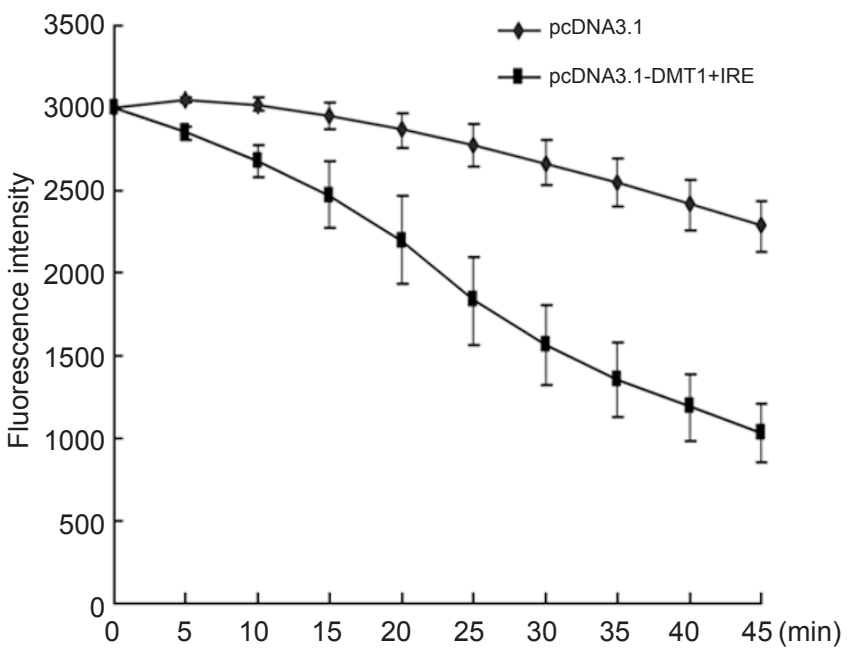

Figure 3 Over-expression of DMT1+IRE enhanced ferrous iron influx in MES23.5 cells. (A) Western blotting was used to detect DMT1+IRE expression in MES23.5 cells after transfection. The protein level was increased to 2.09-fold in the pcDNA3.1DMT1+IRE group compared with the pcDNA3.1 group. $\beta$-Actin was used as a loading control. (B) Statistical analysis. Data are presented as the ratio of DMT1+IRE or DMT1-IRE to $\beta$-actin. Each bar represents the mean \pm S.E.M. of six independent experiments. ${ }^{*} P<0.05$, compared with the pcDNA3.1 group. (C) The ferrous iron influx of MES23.5 cells was measured in different groups. There was a significant decrease in the fluorescence intensity in pcDNA3.1-DMT1+IRE group when perfused with $1 \mathrm{mmol} / \mathrm{L}$ ferrous iron (two-way ANOVA, $\mathrm{F}=25.995, P<0.01$, compared with control). 

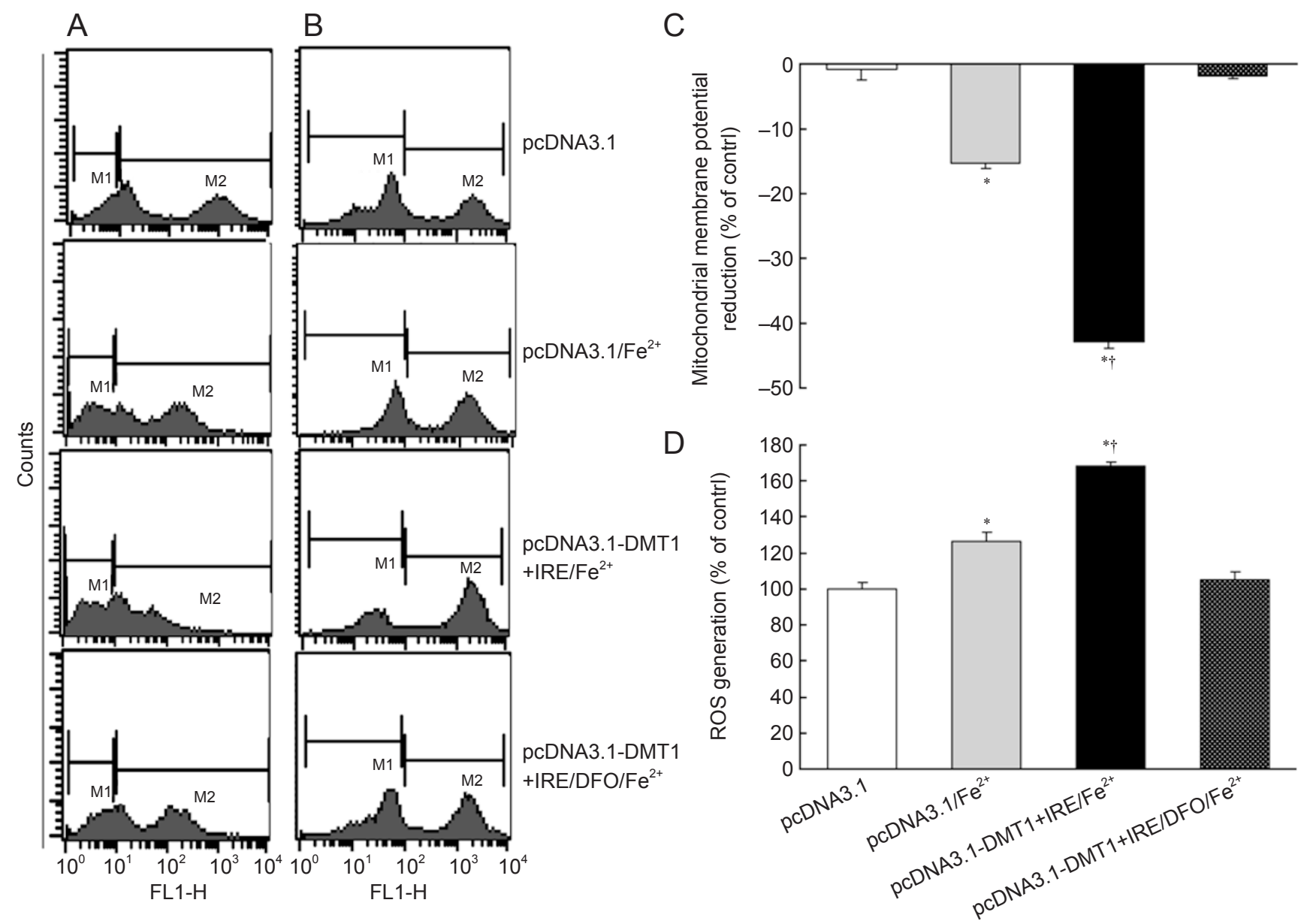

Figure 4 Enhanced iron influx further decreased $\triangle \Psi m$ and increased ROS generation in MES23.5 cells. (A, B) Representative fluorometric assays of $\triangle \Psi \mathrm{m}$ and ROS generation in different groups. Iron incubation for $4 \mathrm{~h}$ in the pcDNA3.1-DMT1+IRE group further decreased $\triangle \Psi \mathrm{m}$ and increased ROS generation compared with the pcDNA3.1 group; pretreatment with DFO fully abolished these effects. (C, D) Statistical analysis. Data are presented as means \pm S.E.M. of six independent experiments. Fluorescence values of the pcDNA3.1 group were set to $100 \%$. ${ }^{*} P<0.05$, compared with the pcDNA3.1 group without iron incubation. ${ }^{\dagger} P<0.05$, compared with the pcDNA3.1 group with iron incubation.

that increased DMT1+IRE expression could aggravate iron-induced oxidative stress. Pretreatment with the iron chelator desferrioxamine mesylate (DFO) fully abolished the $\Delta \Psi \mathrm{m}$ reduction and ROS generation induced by iron. DFO treatment alone had no effect on $\Delta \Psi \mathrm{m}$ or ROS (data not shown) [12].

\section{Up-regulation of DMT1+IRE was IRE/IRP dependent}

Since the main difference between DMT1+IRE and DMT1-IRE proteins is the presence or absence of IRE in the $3^{\prime}$-UTR of their mRNAs, we surmised that 6-OHDAinduced differential regulation of DMT1 might be due to this IRE. Therefore, we investigated the expression of IRPs, IRE-binding proteins, in 6-OHDA-treated MES23.5 cells. IRP1 and IRP2 are the main proteins that register cytosolic iron concentration and post- transcriptionally regulate the expression of genes related to iron metabolism. As expected, IRP1 and IRP2 protein levels were increased 1.41 fold and 1.4 fold, respectively, in 6-OHDA-treated MES23.5 cells (Figure 5A and $5 \mathrm{~B}$ ). The expression of transferrin receptor 1 (TfR1), which is tightly regulated by the IRP-IRE system, was found increased by $2.098 \pm 0.07$-fold $(P<0.05)$, further confirming the increased IRP binding activity with IRE. To further confirm the roles of IRP1 and IRP2 in 6-OHDA-induced DMT1+IRE up-regulation, we constructed small interfering RNA (siRNA) expression vectors for silencing IRP1 or IRP2 expression. With RNA interference, IRP1 expression level was significantly reduced, to $29 \%$ of control, and IRP2 expression level was reduced to $35 \%$ of control (Figure 6A and 6B). When MES23.5 cells with IRP knockdown were treated with 6-OHDA, 
A

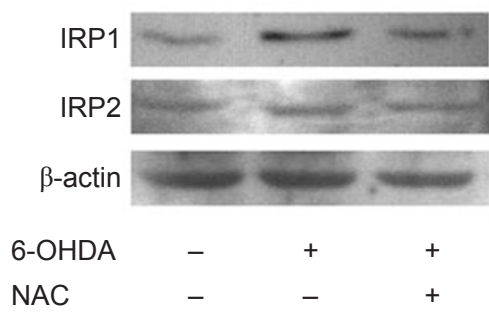

B

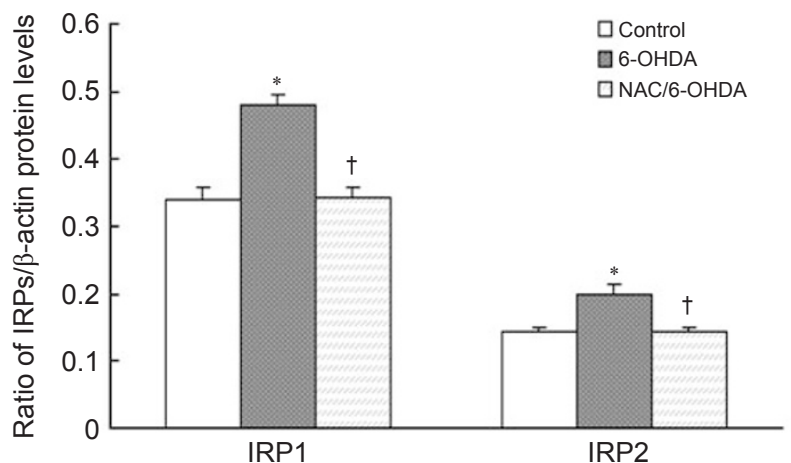

Figure 5 IRP1 and IRP2 expression in MES23.5 cells with 6-OHDA treatment. 6-OHDA induced IRP1 and IRP2 up-regulation in MES23.5 cells and these effects could be fully abolished by NAC pretreatment. (A) Western blotting was used to detect IRP1 and IRP2 expression in 6-OHDA-treated MES23.5 cells. Both IRP1 and IRP2 were up-regulated in 6-OHDA-treated MES23.5 cells. $\beta$-Actin was used as a loading control. The upregulation of IRPs induced by 6-OHDA was fully abolished by NAC pretreatment. (B) Statistical analysis. Data are presented as the ratio of IRP1 or IRP2 to $\beta$-actin. Each bar represents the mean \pm S.E.M. of six independent experiments. ${ }^{*} P<0.05$, compared with control. ${ }^{\dagger} P<0.05$, compared with the 6-OHDA group.

Figure 6 SiRNA-induced IRP1 or IRP2 knockdown partially blocked the up-regulation of DMT1+IRE. (A) IRP1 or IRP2 protein levels were significantly decreased with IRP1 or IRP2 RNA interference, respectively. $\beta$-Actin was used as a loading control. (B) Statistical analysis. Data are presented as the ratio of IRP1 or IRP2 to $\beta$-actin. Each bar represents the mean \pm S.E.M of six independent experiments. ${ }^{*} P<0.05$, compared with control. Real-time PCR and western blotting were used to detect DMT1+IRE mRNA (C) and protein (E) expression in MES23.5 cells. Decreased expression of DMT1+IRE was observed in MES23.5 cells with IRP1 or IRP2 RNA interference. DMT1+IRE mRNA and protein levels were up-regulated with 6-OHDA treatment in control, pSilencer, pSilencer-IRP1 and pSilencerIRP2 groups. However, less up-regulation of DMT1+IRE was observed in pSilencer-IRP1 and pSilencer-IRP2 groups compared with the pSilencer group (D, F). ${ }^{*} P<0.05$, compared with control. ${ }^{\dagger} P<0.05$, compared with the pSilencer group without 6-OHDA treatment. ${ }^{\ddagger} P<0.05$, compared with the pSilencerIRP1 group without 6 -OHDA treatment. ${ }^{\S} P<0.05$, compared with the pSilencer-IRP2 group without 6-OHDA treatment. " $P<$ 0.05 , compared with the pSilencer group.
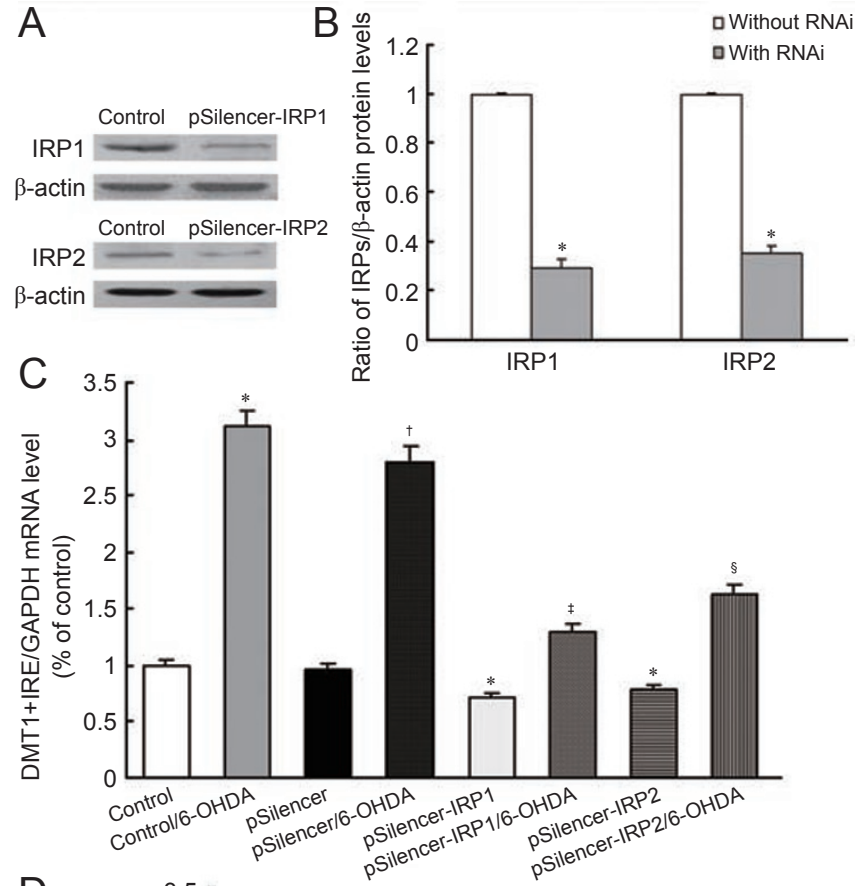

D

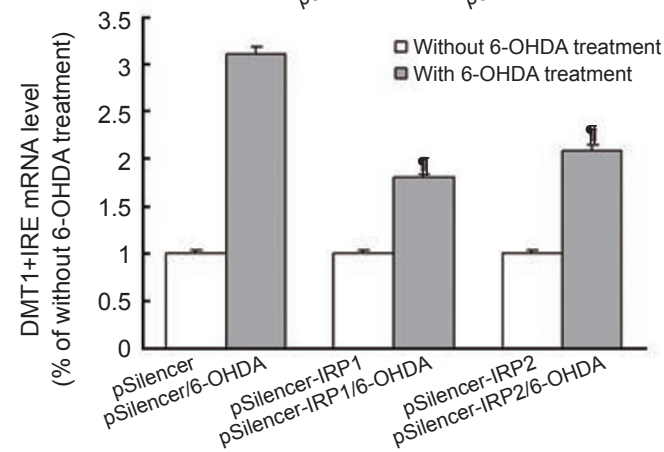

$E$
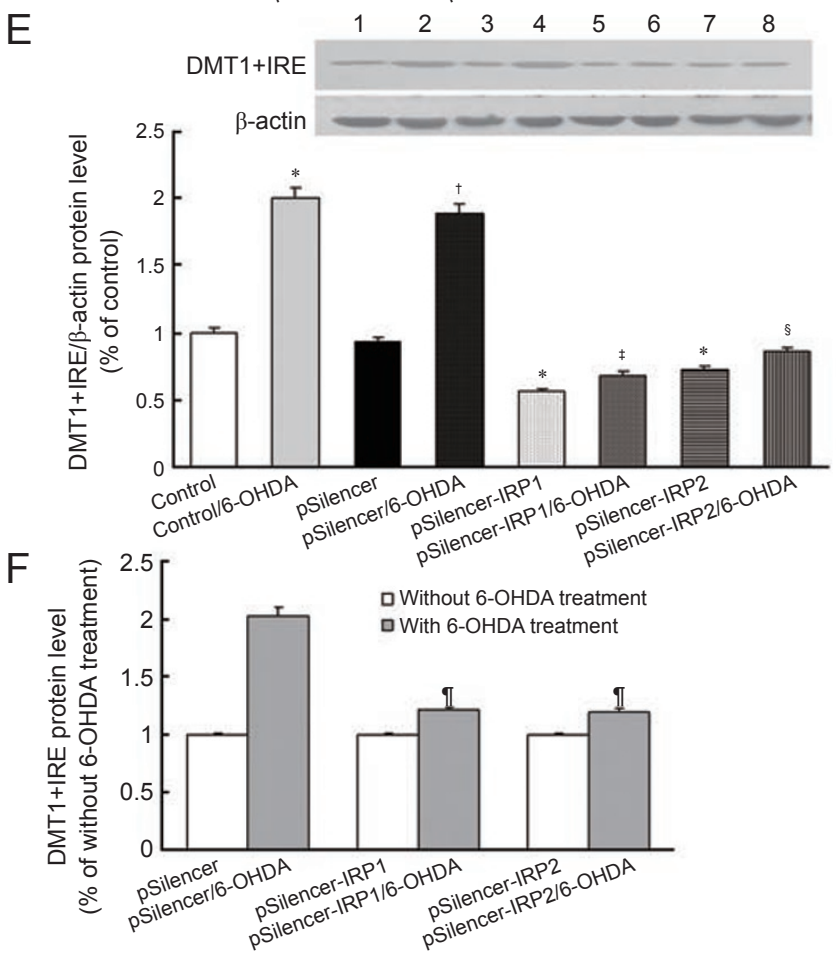

Cell Research | Vol 20 No 3 | March 2010 
the up-regulation of DMT1+IRE by 6-OHDA was partially reversed, as shown by both real-time PCR and western blotting (Figure 6C-6F). The vacant vector had no effect on DMT1+IRE expression either in control or in 6-OHDA-treated cells. However, in control cells, silencing of IRP1 or IRP2 resulted in a relatively small down-regulation of DMT1+IRE, likely because (according to the IRE/IRP theory) the low levels of intracellular IRPs exert a direct post-transcriptional regulation on DMT1 expression. This is further confirmed by the finding that MES23.5 cells with IRP1 over-expression showed increased DMT1+IRE expression (Figure 7). The results indicate that IRPs were involved in the 6-OHDAinduced up-regulation of DMT1+IRE in MES23.5 cells.

Up-regulation of IRPs was initiated by 6-OHDA-induced oxidative stress

Our next experimental goal was to determine the cause of IRP up-regulation in 6-OHDA-treated cells. Oxidative stress is involved in the up-regulation of both IRP1 and IRP2 [13-16]; this was further confirmed by

A

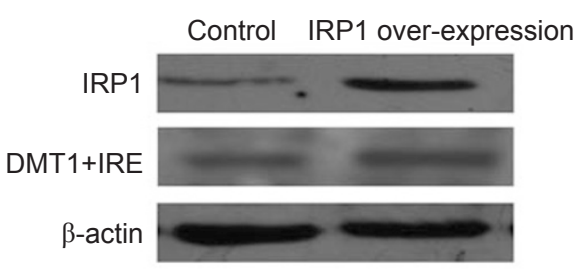

B

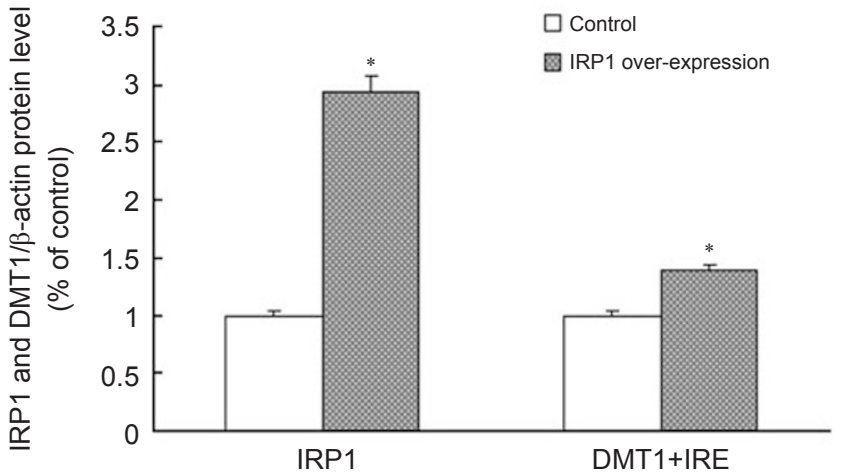

Figure 7 IRP1 over-expression induced DMT1+IRE up-regulation in MES23.5 cells. (A) Both IRP1 and DMT1+IRE protein levels were significantly increased in MES23.5 cells with pCMVAC-ACO1 (IRP1) transfection. $\beta$-Actin was used as a loading control. (B) Statistical analysis. Data are presented as the ratios of IRP1 or DMT1+IRE to $\beta$-actin. Each bar represents the mean \pm S.E.M. of six independent experiments. ${ }^{*} P<0.05$, compared with control.
A

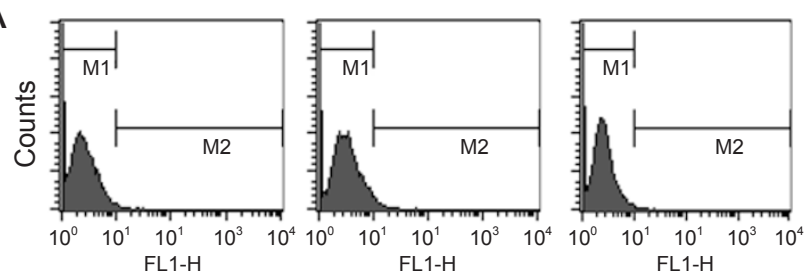

B

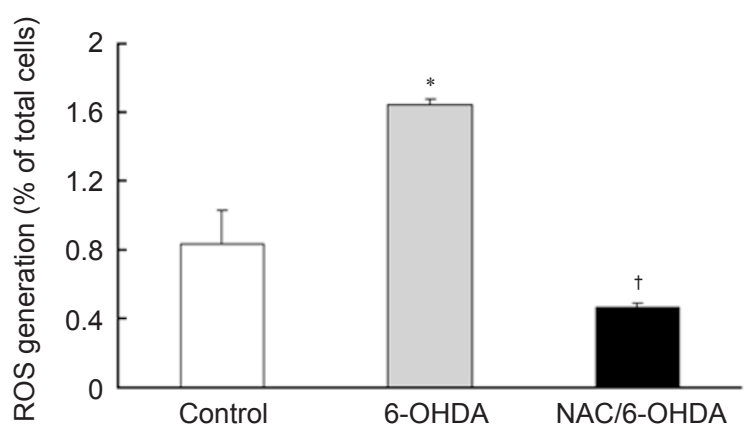

Figure 8 ROS generation in MES23.5 cells with 6-OHDA treatment. 6-OHDA induced significant ROS generation in MES23.5 cells and this effect was fully abolished and even reversed by NAC pretreatment. (A) Representative fluorometric assays of ROS generation. (B) Statistical analysis. Data are presented as mean \pm S.E.M. of six independent experiments. Fluorescence values of the control were set to $100 \%$. ${ }^{*} P<0.05$, compared with control. ${ }^{\dagger} P<0.05$, compared with cells with 6 -OHDA treatment.

the report that the ROS scavengers NAC and ascorbate could attenuate IRP2 up-regulation [17]. Therefore, we hypothesized that up-regulation of IRP1 and/or IRP2 might be initiated by intracellular oxidative stress. To test this hypothesis, changes in intracellular ROS levels upon 6-OHDA treatment in MES23.5 were quantified using flow cytometry. A significantly increased level of ROS was observed in these cells. However, pretreatment with NAC could fully abolish 6-OHDA-induced ROS increase (Figure 8). Furthermore, both IRP1 and IRP2 expression returned to the basal level in 6-OHDA-treated MES23.5 cells with NAC pretreatment (Figure 5). This indicated that IRPs were up-regulated by 6-OHDA-induced ROS formation.

\section{Discussion}

In this study, we demonstrated the following: first, DMT1+IRE, but not DMT1-IRE, was up-regulated in vivo in the SN of 6-OHDA-induced $\mathrm{PD}$ rats, which was accompanied by increased iron staining in this region. Second, DMT1+IRE was up-regulated in vitro in 6-OHDA-treated MES23.5 cells, which accounted for 
the increased ferrous iron influx. Over-expression of DMT1 caused increased iron influx, resulting in damaged mitochondrial function and increased ROS generation and leading to aggravated oxidative stress. Third, DMT1+IRE up-regulation occurred in an IRE/IRP-dependent manner and was initiated by 6 -OHDA-induced oxidative stress.

6-OHDA lesioning is a well-established method for preparation of PD animal models [18-20]. 6-OHDAtreated animals exhibit the major hallmarks of PD, including loss of dopaminergic neurons in the SN. In the present study, we observed increased iron levels in the SN of PD models where dopaminergic neuronal degeneration was found, in accordance with our previous studies as well as with those of others [7, 21, 22]. Ferrous iron is harmful to cells because of its ability to react with hydrogen peroxide to form highly reactive hydroxyl radicals. At present, one of the iron transporters that contribute to ferrous iron transport is DMT1; therefore, we investigated its expression in vivo in 6-OHDA-induced PD rats. DMT1+IRE, but not DMT1-IRE, was up-regulated in affected SN where iron deposit was observed. Our previous studies showed that iron accumulation can cause down-regulation of DMT1 [11]. Therefore, 6-OHDA-induced DMT1 up-regulation might be the primary cause, not a secondary event, of the iron accumulation observed in PD rats. To further elucidate the underlying mechanisms, MES23.5 cells, which possess at least three neuronal features, namely, tyrosine hydroxylase expression, dopamine synthesis system, and omega-conotoxin receptor expression, were used in vitro [23]. Since these cells exhibit several properties similar to those of primary neurons of the $\mathrm{SN}$, the results from this cell line can provide direct evidence correlating with the degeneration of dopaminergic neurons in PD. Similar to the results of our in vivo study, DMT1+IRE was up-regulated in 6-OHDA-treated MES23.5 cells, followed by increased ferrous iron influx. This was further confirmed by results in MES23.5 cells over-expressing DMT1+IRE. As we have shown, the increased intracellular iron caused by the over-expression of DMT1+IRE increased ROS generation and decreased $\Delta \Psi \mathrm{m}$ and both changes could be fully suppressed by the iron chelator DFO. These results are consistent with results from our in vivo studies showing that DFO could prevent the progressive loss of dopaminergic neurons [24], and are also supported by other evidence indicating that administration of the iron chelators DFO and VK-28 to 6-OHDA-treated rats can prevent the neurotoxic action of this compound and exert significant neuroprotective effects $[8,25]$, which may be a consequence of chelation of the increased intracellular iron induced by 6 -OHDA. These results indicate that
DMT1+IRE might be involved in selective iron accumulation in the SN of PD.

Interestingly, we observed up-regulation of DMT1+IRE, but not DMT1-IRE, mRNA and protein levels in 6-OHDA-treated rats and MES23.5 cells. The main difference between DMT1+IRE and DMT1-IRE is that DMT1+IRE contains IRE in the $3^{\prime}$-UTR of its mRNA, while DMT1-IRE does not. IRE is known to be a binding site for IRPs, which can sense intracellular iron status and participate in the maintenance of cellular iron homeostasis. IRP binding to IRE could post-transcriptionally regulate the expression of some genes involved in iron metabolism. In mammalian cells, IRP1 maintains its ability to function as an aconitase, whereas IRP2 is the chief physiological iron sensor. Under certain circumstances, IRPs can be activated by certain agents $[13,14$, 26]. Depending on the site of IRE (whether in 5'- or 3'UTR), IRP binding to IRE could repress mRNA translation or increase mRNA stability. In the present study, increased expression of IRP1 and IRP2 was observed after 6-OHDA treatment, which might, according to the IRE/ IRP theory, bind to the IRE in the 3'-UTR of DMT1+IRE mRNA and increase its stability. TfR1, which has an IRE in the 3'-UTR similar to DMT1+IRE, was also upregulated, further supporting the increased IRP-binding activity with IRE. The function of IRE in the DMT1+IRE mRNA was further confirmed by our observation that IRP knockdown could lower DMT1+IRE level in both control and 6-OHDA-treated cells. On the other hand, IRP1 over-expression caused increased DMT1+IRE expression in MES23.5 cells. The absence of IRE in the DMT1-IRE form can account for its unchanged expression after 6-OHDA treatment. These observations suggest that a functional IRE exists in DMT1+IRE mRNA and are consistent with results of other studies suggesting that IRPs can regulate the expression levels of DMT1 mRNA and protein [27-29]. However, it is difficult to tell which of the two IRPs is primarily involved in DMT1 regulation according to our present data. Further work is necessary to sort this out in the future.

6-OHDA was highly effective in vitro in releasing iron from its binding sites ferritin [30]. However, increased intracellular iron would lead to the degradation of IRP2 and alternate IRP1 to cytosolic aconitase. Therefore, other mechanisms must be involved in 6-OHDA-induced up-regulation of IRPs. 6-OHDA, once dissolved in an aerobic and alkaline milieu, readily oxidizes [31, 32], and it has been reported that 6-OHDA can exert extracellular toxic effects because of its extracellular auto-oxidation $[33,34]$. The oxidative products of 6-OHDA can then further initiate intracellular oxidative stress, which might be a key mediator of neurodegeneration in PD. Oxidative 
stress could activate IRPs by other, not yet fully elucidated pathways $[13,17,35]$. In the present study, the antioxidant NAC fully prevented ROS generation induced by 6-OHDA and the subsequent activation of IRPs, further supporting the participation of oxidative stress in IRP activation. However, there are other mechanisms by which NAC could directly down-regulate the expression of IRPs by promoting proteasomal degradation [36]. Taken together, our results suggest that 6-OHDA-induced upregulation of DMT1+IRE is likely to be due to the activation of IRPs by 6-OHDA-induced oxidative stress.

Our experiments demonstrated that 6-OHDA-induced iron accumulation occurred following the up-regulation of DMT1+IRE by IRP activation induced by oxidative stress. In such a cycle, the products of oxidative stress would result in a positive feedback, ultimately causing cell death. Our experiment also suggested that DMT1, especially the +IRE form, might be involved in the neurotoxicity of 6-OHDA. From a novel perspective, this study provides direct evidence for DMT1 up-regulation and supports the administration of anti-oxidants in the treatment of PD as a means of inhibiting iron accumulation through regulation of IRPs and DMT1 expression.

\section{Materials and Methods}

\section{Materials}

All procedures were carried out in accordance with the NIH Guide for the Care and Use of Laboratory Animals and the Guidelines for the Use of Animals in Neuroscience Research. Female Wistar rats weighing 200-220 g were given free access to food and water and kept in a $12 \mathrm{~h}$ light/dark cycle. 6-OHDA, DFO, apomorphine, $\mathrm{FeSO}_{4} \cdot 7 \mathrm{H}_{2} \mathrm{O}$, NAC and Rhodamine123 (Rh123) were from Sigma Chemical Co. (St Louis, MO, USA). Primary antibodies against DMT1 \pm IRE, IRP1 and IRP2 were from ADI (San Antonio, TX, USA). Carboxy- $\mathrm{H}_{2}$ DCFDA and calcein-AM were from Molecular Probes (Molecular Probes Inc., Carlsbad, CA, USA). Dulbecco's modified Eagle's medium Nutrient Mixture-F12 [37] (DMEM/F12) was from Gibco (Grand Island, NY, USA). Lipofectamine $^{\mathrm{TM}} 2000$ was from Invitrogen (CA, USA); pSilencerTM1.0-U6 vector was from Ambion (Austin, TX, USA). pCMV6AC-ACO1 (IRP1) was from Origen (Beijing, China). All other chemicals and regents were of the highest grade available from local commercial sources.

\section{6-OHDA lesions and rotational behavior tests}

6-OHDA lesions were performed as previously described [7, 38-40]. Briefly, rats were anesthetized with chloral hydrate (400 $\mathrm{mg} / \mathrm{kg}$, i.p.) and mounted onto a stereotaxic frame. One burr hole ( $2.5 \mathrm{~mm}$ diameter) was drilled into the skull above the region of the left medial forebrain bundle (MFB), according to the coordinates of Paxinos and Watson. Two microinjections of 6-OHDA (3.6 $\mathrm{mg} / \mathrm{mL}$ dissolved in saline containing $0.2 \mathrm{mg} / \mathrm{mL}$ L-ascorbate) were made into the left MFB: (1) TB - $2.3 \mathrm{~mm}$; AP - $4.4 \mathrm{~mm}$; ML $1.2 \mathrm{~mm}$; V $7.8 \mathrm{~mm}$ and (2) TB + $3.4 \mathrm{~mm}$; AP - $4.0 \mathrm{~mm}$; ML 0.8 $\mathrm{mm}$; V $8.0 \mathrm{~mm}$. Volumes of 2.5 and $3.0 \mu \mathrm{L}$ of 6-OHDA, respec- tively, were microinjected into these sites at a rate of $1.0 \mu \mathrm{L} / \mathrm{min}$. After the injection, the microinjection needle was left in place for a further 5 min before being slowly extracted.

Fourteen days after 6-OHDA injection, rats were tested for rotational behavior with apomorphine $(0.05 \mathrm{mg} / \mathrm{kg}$, s.c. $)$ in 'rotameter' bowls for $60 \mathrm{~min}$. Rotational behavior was tested 3 times at intervals of 2 weeks. Rats reaching a level of at least 7 rotations $/ \mathrm{min}$ were regarded as PD model rats. Control animals received injections of saline containing $0.2 \mathrm{mg} / \mathrm{mL} \mathrm{L}$-ascorbate.

\section{Iron staining by Perls' Prussian blue reaction}

Perls' Prussian blue staining was performed as previously described [37]. Rats were deeply anesthetized ( $8 \%$ chloral hydrate, i.p.) and transcardially perfused with normal saline and $4 \%$ paraformaldehyde in $0.1 \mathrm{~mol} / \mathrm{L}$ phosphate-buffered saline (PBS, $\mathrm{pH}$ 7.4). Brain blocks containing the $\mathrm{SN}$ were sectioned coronally at $20 \mu \mathrm{m}$ on a freezing microtome (Leica). The sections were mounted on polylysine-coated slides and washed with $0.01 \mathrm{~mol} / \mathrm{L}$ PBS, fixed in 4\% paraformaldehyde for $5 \mathrm{~min}$, and washed for 30 $\mathrm{s}$ in Milli-Q water prior to staining. Sections were immersed for $30 \mathrm{~min}$ in a freshly prepared solution of one part $2 \% \mathrm{HCl}$ and one part $2 \%$ potassium ferrocyanide, followed by three washes with PBS. Negative control sections were prepared in which the $\mathrm{HCl}$ and potassium ferrocyanide solutions were omitted. The sections were then immersed in $99 \%$ methanol and $1 \%$ hydrogen peroxide for 20 min to eliminate endogenous peroxidase activity. The DAB reaction product was observed under an Olympus microscope. All incubations and washes were performed in polypropylene troughs that had been washed in $10 \% \mathrm{HCl}(<0.02 \mathrm{ppm} \mathrm{Fe})$ overnight and rinsed in Milli-Q water. One section was chosen from every three sections throughout the SNpc per brain. Sections were focused using an 20× objective lens (Olympus) and the images were captured by a video camera (Olympus) at a final magnification of $200 \times$. We took four images from one section and the positive cells were calculated at an average owing to there being not too many positive cells. An average number of positive cells throughout the entire rostrocaudal extent of the SNpc was shown [41].

\section{Total RNA extraction and quantitative PCR}

Total RNA was isolated from the SN of the PD rats using Trizol Reagent (Invitrogen) according to the manufacturer's instructions. Then $2 \mu \mathrm{g}$ total RNA was reverse transcribed in a $20 \mu \mathrm{L}$ reaction using a reverse-transcription system (Promega). Quantitative PCR was employed to detect changes in DMT1 \pm IRE and TfR1. TaqMan probe and primers were designed using the default settings of Primer Express 2.0 (PE Applied Biosystems). Each set of primers was used with a TaqMan probe labeled at the $5^{\prime}$-end with 6-carboxyfluorescein (FAM) reporter dye and at the 3 '-end with 6-carboxy-tetramethylrhodamine (TAMRA) quencher dye. The following primers and probes were employed for DMT1+IRE, DMT1-IRE and TfR1: DMT1+IRE forward 5'-TGG CTG TCA CGA GTG CTT ACA-3', reverse 5'-CCA TGG CCT TGG ACA GCT ATT-3', and probe 5'-TTA CCC TGT AGC ATT AGG CAG CAC C-3'; DMT1-IRE forward 5'-AAG CCC TTT TGT GCC AAG TGT-3', reverse 5'-ACC CAT TCA CAG CCG TTA GCT3', and probe 5'-CAA ATG TTT TGA ACC AAG GCG AAG A-3'; TfR1 forward 5'-GGG CAC TAG ATT GGA TAC CTA TGA G-3', reverse 5'-GGT TCA ATT CAA CGT CAT GGG TAA G-3', and probe 5'-CCA CTT CCG CTG CTG TAC GAA CCA T-3'. Rat 
GAPDH gene was used as the reference: forward 5'-CCC CCA ATG TAT CCG TTG TG-3', reverse 5'-GTA GCC CAG GAT GCC CTT TAG T-3', and probe 5'-TCT GAC ATG CCG CCT GGA GAA ACC-3'. Reactions were carried out in an ABI PRISM ${ }^{\circledR} 7500$ Sequence Detection System using the relative quantification option of the SDS1.2.1 software (Applied Biosystems). Each reaction was run in triplicate with $2 \mu \mathrm{L}$ sample in a total volume of $20 \mu \mathrm{L}$ with primers and probes to a final concentration of $0.25 \mu \mathrm{mol} / \mathrm{L}$. A passive reference dye, ROX II, was used to normalize the reporter signal. Amplification and detection were performed with the following conditions: an initial hold at $95{ }^{\circ} \mathrm{C}$ for $10 \mathrm{~s}$, followed by 40 cycles at $95{ }^{\circ} \mathrm{C}$ for $5 \mathrm{~s}$ and $60^{\circ} \mathrm{C}$ for $45 \mathrm{~s}$.

\section{Western blotting analysis}

SN from brains of the PD rats were digested with RIPA lysis buffer $(50 \mathrm{mmol} / \mathrm{L}$ Tris-HCl, $150 \mathrm{mmol} / \mathrm{L} \mathrm{NaCl}, 1 \%$ Nonidet-40, $0.5 \%$ sodium deoxycholate, $1 \mathrm{mmol} / \mathrm{L}$ EDTA, $1 \mathrm{mmol} / \mathrm{L}$ PMSF) with protease inhibitors (pepstatin $1 \mu \mathrm{g} / \mathrm{mL}$, aprotinin $1 \mu \mathrm{g} / \mathrm{mL}$, leupeptin $1 \mu \mathrm{g} / \mathrm{mL}$ ) for $30 \mathrm{~min}$ and the protein concentration was determined using the Bradford assay kit (Bio-Rad Laboratories, Hercules, CA, USA). Eighty micrograms of total protein from each sample was separated using 10\% SDS-polyacrylamide gels and transferred to PVDF membranes. After overnight blocking with $4 \%$ non-fat milk at $4{ }^{\circ} \mathrm{C}$, the membranes were incubated with rabbit-anti-rat DMT1+IRE, DMT1-IRE, IRP1 or IRP2 antibodies $(1: 2000)$ for $1 \mathrm{~h}$ at room temperature. Anti-rabbit secondary antibody conjugated to horseradish peroxidase (Amersham Biosciences, England) was used at 1:2 500. Blots were also probed with anti- $\beta$-actin monoclonal antibody (Sigma, 1:10 000) as a loading control. Cross-reactivity was visualized using ECL Western blotting detection reagents and analyzed by scanning densitometry using a Tanon Image System (Tanon, Shanghai, China).

\section{Cell culture}

MES23.5 cells, a gift from Dr Weidong Le (Baylor College of Medicine, TX, USA), were maintained at $37{ }^{\circ} \mathrm{C}$ in a $95 \%$ air $/ 5 \% \mathrm{CO}_{2}$ humidified atmosphere in polylysine-precoated T-25 flasks in DMEM/F12 containing Sato's components and 5\% heatinactivated FBS. For experiments, cells were seeded at a density of $1 \times 10^{5} / \mathrm{cm}^{2}$ in plastic flasks or on glass coverslips. After treatment with $10 \mu \mathrm{mol} / \mathrm{L}$ 6-OHDA (dissolved in saline containing $2 \mu \mathrm{g} / \mathrm{mL}$ ascorbic acid) for $24 \mathrm{~h}$, total RNA and protein were extracted and the expression of DMT1 \pm IRE at the mRNA and protein levels was determined as described above. NAC $(0.5 \mathrm{mmol} / \mathrm{L})$ was added 30 min prior to 6-OHDA treatment.

\section{Calcein loading of cells and ferrous iron influx assay}

Ferrous iron influx into MES23.5 cells was determined by measuring the quenching of calcein fluorescence as previously described [11, 12, 42-44]. Cells were seeded onto coverslips and grown in serum-free medium with 6-OHDA $(10 \mu \mathrm{mol} / \mathrm{L})$ for 24 $\mathrm{h}$. They were then incubated with calcein-AM $(0.5 \mu \mathrm{mol} / \mathrm{L}$ final concentration) in HEPES-buffered saline (HBS, $10 \mathrm{mmol} / \mathrm{L}$ HEPES, $150 \mathrm{mmol} / \mathrm{L} \mathrm{NaCl}, \mathrm{pH} 7.4$ ) for $30 \mathrm{~min}$ at $37{ }^{\circ} \mathrm{C}$. The excess calcein on the cell surface was washed off three times with HBS. The coverslips were then mounted in a perfused chamber. Calcein fluorescence was recorded at $488 \mathrm{~nm}$ excitation and $525 \mathrm{~nm}$ emission wavelengths and fluorescence intensity was measured every $3 \mathrm{~min}$ for 10 times while perfusing with $1 \mathrm{mmol} / \mathrm{L}$ ferrous iron (ferrous sulfate in ascorbic acid solution, 1:44 molar ratio, $\mathrm{pH}$ 6.0), prepared immediately prior to the experiment. Ascorbic acid maintained the reduced status of ferrous iron. The mean fluorescence signal of 35-40 single cells in four separate fields was monitored at $\times 20$ magnification and processed using Fluoview 5.0 software.

\section{Construction of recombinant vector pcDNA3.1-DMT1+IRE} and selection of stable recombinant cell lines

The full-length human DMT1+IRE sequence was inserted into a stable mammalian vector pcDNA3.1 (Invitrogen) containing the markers of ampR for selection in bacterial cells, neoR for selection and a CMV promoter for expression in mammalian cells. For cloning the full-length DMT1+IRE gene from frozen tissues of human duodenum, PCR was conducted (forward 5'-AAG GTA CCA CCA TGG TGC TGG GTC CTG-3', reverse 5'-CAC AAA GAT ACC AAA TGA CAC ACT TTT CGA AGC-3'); the 1772-bp PCR fragment was cut with restriction enzymes $K p n I$ and $E c o$ R V and inserted into the PMD18-T simple vector (Takara) for cloning and sequencing. The digested fragment DMT1+IRE was inserted into the pcDNA3.1 vector to form the construct denoted pcDNA3.1DMT1+IRE. For large-scale plasmid DNA preparations, the plasmid was transformed into E. coli JM109 and the bacteria were grown in culture medium supplemented with ampicillin. The plasmid was extracted and constructs verified by restriction at multiple cloning sites. MES23.5 cells were seeded in six-well plates; at $80-90 \%$ confluence, and cells were transfected with pcDNA3.1DMT1+IRE using Lipofectamine ${ }^{\mathrm{TM}} 2000$ reagent according to the manufacturer's instructions. Forty-eight hours later, growth medium was replaced with medium containing $700 \mu \mathrm{g} / \mathrm{mL}$ G418. MES23.5 cells were also transfected with pcDNA3.1 blank plasmid as the control. After 12-14 days, G418-resistant clones were selected, clonally isolated and screened further for mRNA and protein expression. Stable cell lines with over-expression of DMT1 were used for iron influx assays as described above.

\section{Flow cytometric measurement of $\triangle \Psi m$ and $R O S$}

Changes in the $\Delta \Psi \mathrm{m}$ and levels of intracellular ROS with iron treatment of MES23.5 were measured using flow cytometry with Rh123 or carboxy- $\mathrm{H}_{2}$ DCFDA dye, as previously described $[12,45$, 46]. Cells transfected with pcDNA3.1 or pcDNA3.1-DMT1+IRE were incubated in $100 \mu \mathrm{mol} / \mathrm{L}$ ferrous iron $(\mathrm{pH} 6.0)$ for $4 \mathrm{~h}$. After cells were washed with HBS three times, carboxy- $\mathrm{H}_{2}$ DCFDA (5 $\mu \mathrm{mol} / \mathrm{L}$ ) was added and incubation was performed for $30 \mathrm{~min}$ at $37{ }^{\circ} \mathrm{C}$. Cells were washed twice with HBS, followed by centrifugation at $800 \mathrm{rpm}$ for $5 \mathrm{~min}$, and re-suspended in $1 \mathrm{~mL}$ HBS. To further confirm that the intracellular oxidative damage was due to high iron levels, cells were pretreated with iron chelator- $1 \mathrm{mmol} /$ L DFO for $3 \mathrm{~h}$ before ferrous iron incubation. Intracellular ROS generation was also assayed in 6-OHDA-treated MES23.5 cells. Fluorescent intensity was recorded at $488 \mathrm{~nm}$ excitation and 525 $\mathrm{nm}$ emission wavelengths (Fluorescence 1, FL1). Results were demonstrated as FL1-H (Fluorescence 1-Histogram), setting the gated region M1 and M2 as a marker to observe the changing levels of fluorescence intensity using Cellquest Software.

\section{Construction of SiRNA expression vectors for IRPS and transfection of MES23.5 cells \\ $\mathrm{p}$ Silencer ${ }^{\mathrm{TM}} 1.0-\mathrm{U} 6$ was used for constructing siRNA expression} vectors targeting IRP1 or IRP2 mRNA. The sequences of the siR- 
NAs for IRP1 and IRP2 were taken from GenBank accession No. NM_017321 (nucleotides $1297-1315$ or 2 055-2 073 from the start codon) and NM 022863 (nucleotides 1 679-1 697 or 1739 1757 from the start codon), respectively. Annealed oligonucleotides containing the 9-nt spacer and five Ts were inserted into the pSilencer ${ }^{\mathrm{TM}} 1.0-\mathrm{U} 6$ vector digested with ApaI and EcoRI according to the manufacturer's instructions. MES23.5 cells were transfected using pSilencer ${ }^{\mathrm{TM}} 1.0-\mathrm{U} 6-\mathrm{IRP} 1$ or $\mathrm{p}$ Silencer ${ }^{\mathrm{TM}} 1.0-\mathrm{U} 6-\mathrm{IRP} 2$ as described above and harvested after $48 \mathrm{~h}$. MES23.5 cells were also transfected with pSilencer ${ }^{\mathrm{TM}} 1.0-\mathrm{U} 6$ blank plasmid as a control. Sequences 1 297-1 315 bases from the start codon for IRP1 and 1 679-1 697 from the start codon for IRP2 were chosen for optimal interfering efficiency. MES23.5 cells were also transfected with pCMV6-AC-ACO1 (IRP1); Western blotting was used to detect IRP1 and DMT1+IRE expression.

\section{Statistical analysis}

Results are presented as means \pm S.E.M. Differences between means in two groups were compared using the unpaired-samples $t$ test. One-way analysis of variance (ANOVA) followed by the Student-Newman-Keuls test was used to compare difference between means in more than two groups. Influx studies were carried out using two-way ANOVA followed by the Student-Newman-Keuls test; data are presented as means \pm S.D. A probability of $P<0.05$ was taken to indicate statistical significance.

\section{Acknowledgments}

We thank Dr Wei-dong Le for providing the MES23.5 cell line. This work was supported by grants from the National Program of Basic Research sponsored by the Ministry of Science and Technology of China (2006CB500704), the National Natural Science Foundation of China $(30930036,30770757,30870858)$ and the Natural Science Fund of Shandong Province for Distinguished Young Scholars (JQ200807).

\section{References}

1 Berg D, Hochstrasser H. Iron metabolism in Parkinsonian syndromes. Mov Disord 2006; 21:1299-1310.

2 Berg D, Youdim MB. Role of iron in neurodegenerative disorders. Top Magn Reson Imaging 2006; 17:5-17.

3 Jiang H, Qian ZM, Xie JX. [Increased DMT1 expression and iron content in MPTP-treated C57BL/6 mice]. Sheng Li Xue Bao 2003; 55:571-576.

4 Xie JX, Jiang H, Chen WF, Qian ZM. Dopamine release rather than content in the caudate putamen is associated with behavioral changes in the iron rat model of Parkinson's disease. Exp Neurol 2003; 182:483-489.

5 Martin WR, Wieler M, Gee M. Midbrain iron content in early Parkinson disease: a potential biomarker of disease status. Neurology 2008; 70 (Pt 2):1411-1417.

6 Salazar J, Mena N, Hunot S, et al. Divalent metal transporter 1 (DMT1) contributes to neurodegeneration in animal models of Parkinson's disease. Proc Natl Acad Sci USA 2008; 105:18578-18583.

7 Wang J, Jiang H, Xie JX. Time dependent effects of 6-OHDA lesions on iron level and neuronal loss in rat nigrostriatal system. Neurochem Res 2004; 29:2239-2243.
8 Youdim MB, Stephenson G, Ben Shachar D. Ironing iron out in Parkinson's disease and other neurodegenerative diseases with iron chelators: a lesson from 6-hydroxydopamine and iron chelators, desferal and VK-28. Ann N Y Acad Sci 2004; 1012:306-325.

9 Zecca L, Youdim MB, Riederer P, Connor JR, Crichton RR. Iron, brain ageing and neurodegenerative disorders. Nat Rev Neurosci 2004; 5:863-873.

10 Oakley AE, Collingwood JF, Dobson J, et al. Individual dopaminergic neurons show raised iron levels in Parkinson disease. Neurology 2007; 68:1820-1825.

11 Song N, Jiang H, Wang J, Xie JX. Divalent metal transporter 1 up-regulation is involved in the 6-hydroxydopamineinduced ferrous iron influx. J Neurosci Res 2007; 85:31183126.

12 Zhang S, Wang J, Song N, Xie J, Jiang H. Up-regulation of divalent metal transporter 1 is involved in 1-methyl-4-phenylpyridinium $(\mathrm{MPP}(+))$-induced apoptosis in MES23.5 cells. Neurobiol Aging 2009; 30:1466-1476.

13 Hentze MW, Kuhn LC. Molecular control of vertebrate iron metabolism: mRNA-based regulatory circuits operated by iron, nitric oxide, and oxidative stress. Proc Natl Acad Sci USA 1996; 93:8175-8182.

14 Nunez-Millacura C, Tapia V, Munoz P, Maccioni RB, Nunez MT. An oxidative stress-mediated positive-feedback iron uptake loop in neuronal cells. J Neurochem 2002; 82:240-248.

15 Regan RF, Chen M, Li Z, et al. Neurons lacking iron regulatory protein-2 are highly resistant to the toxicity of hemoglobin. Neurobiol Dis 2008; 31:242-249.

16 Regan RF, Li Z, Chen M, Zhang X, Chen-Roetling J. Iron regulatory proteins increase neuronal vulnerability to hydrogen peroxide. Biochem Biophys Res Commun 2008; 375:6-10.

17 Niles BJ, Clegg MS, Hanna LA, et al. Zinc deficiency-induced iron accumulation, a consequence of alterations in iron regulatory protein-binding activity, iron transporters, and iron storage proteins. J Biol Chem 2008; 283:5168-5177.

18 Deumens R, Blokland A, Prickaerts J. Modeling Parkinson's disease in rats: an evaluation of 6-OHDA lesions of the nigrostriatal pathway. Exp Neurol 2002; 175:303-317.

19 Kaariainen TM, Piltonen M, Ossola B, et al. Lack of robust protective effect of quercetin in two types of 6-hydroxydopamine-induced parkinsonian models in rats and dopaminergic cell cultures. Brain Res 2008; 1203:149-159.

20 Weng Z, Signore AP, Gao Y, et al. Leptin protects against 6-hydroxydopamine-induced dopaminergic cell death via mitogen-activated protein kinase signaling. J Biol Chem 2007; 282:34479-34491.

21 Ma ZG, Wang J, Jiang H, Liu TW, Xie JX. Myricetin reduces 6-hydroxydopamine-induced dopamine neuron degeneration in rats. Neuroreport 2007; 18:1181-1185.

22 Mandel S, Grunblatt E, Riederer P, et al. Neuroprotective strategies in Parkinson's disease: an update on progress. CNS Drugs 2003; 17:729-762.

23 Crawford GD Jr, Le WD, Smith RG, et al. A novel N18TG2 $\mathrm{x}$ mesencephalon cell hybrid expresses properties that suggest a dopaminergic cell line of substantia nigra origin. $J$ Neurosci 1992; 12:3392-3398.

24 Jiang H, Luan Z, Wang J, Xie J. Neuroprotective effects of iron chelator Desferal on dopaminergic neurons in the sub- 
stantia nigra of rats with iron-overload. Neurochem Int 2006; 49:605-609.

25 Shachar DB, Kahana N, Kampel V, Warshawsky A, Youdim MB. Neuroprotection by a novel brain permeable iron chelator, VK-28, against 6-hydroxydopamine lession in rats. $\mathrm{Neu}$ ropharmacology 2004; 46:254-263.

26 Wang L, Wang W, Zhao M, Ma L, Li M. Psychological stress induces dysregulation of iron metabolism in rat brain. Neuroscience 2008; 155:24-30.

27 Galy B, Ferring-Appel D, Kaden S, Grone HJ, Hentze MW. Iron regulatory proteins are essential for intestinal function and control key iron absorption molecules in the duodenum. Cell Metab 2008; 7:79-85.

28 Huang E, Ong WY, Go ML, Connor JR. Upregulation of iron regulatory proteins and divalent metal transporter-1 isoforms in the rat hippocampus after kainate induced neuronal injury. Exp Brain Res 2006; 170:376-386.

29 Kato J, Kobune M, Ohkubo S, et al. Iron/IRP-1-dependent regulation of mRNA expression for transferrin receptor, DMT1 and ferritin during human erythroid differentiation. Exp Hematol 2007; 35:879-887.

30 Double KL, Maywald M, Schmittel M, Riederer P, Gerlach M. In vitro studies of ferritin iron release and neurotoxicity. $J$ Neurochem 1998; 70:2492-2499.

31 Heikkila R, Cohen G. Inhibition of biogenic amine uptake by hydrogen peroxide: a mechanism for toxic effects of 6-hydroxydopamine. Science 1971; 172:1257-1258.

32 Saner A, Thoenen H. Model experiments on the molecular mechanism of action of 6-hydroxydopamine. Mol Pharmacol 1971; 7:147-154.

33 Blum D, Torch S, Nissou MF, Benabid AL, Verna JM. Extracellular toxicity of 6-hydroxydopamine on PC12 cells. Neurosci Lett 2000; 283:193-196.

34 Hanrott K, Gudmunsen L, O’Neill MJ, Wonnacott S. 6-hydroxydopamine-induced apoptosis is mediated via extracellular auto-oxidation and caspase 3-dependent activation of protein kinase Cdelta. J Biol Chem 2006; 281:5373-5382.

35 Pantopoulos K, Weiss G, Hentze MW. Nitric oxide and oxidative stress $\left(\mathrm{H}_{2} \mathrm{O}_{2}\right)$ control mammalian iron metabolism by dif- ferent pathways. Mol Cell Biol 1996; 16:3781-3788.

36 Wang J, Chen G, Muckenthaler M, et al. Iron-mediated degradation of IRP2, an unexpected pathway involving a 2-oxoglutarate-dependent oxygenase activity. Mol Cell Biol 2004; 24:954-965.

37 Morris CM, Candy JM, Oakley AE, Bloxham CA, Edwardson JA. Histochemical distribution of non-haem iron in the human brain. Acta Anat (Basel) 1992; 144:235-257.

38 Earl CD, Reum T, Xie JX, et al. Foetal nigral cell suspension grafts influence dopamine release in the non-grafted side in the 6-hydroxydopamine rat model of Parkinson's disease: in vivo voltammetric data. Exp Brain Res 1996; 109:179-184.

39 Wang J, Jiang H, Xie JX. Ferroportin1 and hephaestin are involved in the nigral iron accumulation of 6-OHDA-lesioned rats. Eur J Neurosci 2007; 25:2766-2772.

40 Zhou Y, Zhao ZQ, Xie JX. Effects of isatin on rotational behavior and DA levels in caudate putamen in Parkinsonian rats. Brain Res 2001; 917:127-132.

41 Jiang H, Li LJ, Wang J, Xie JX. Ghrelin antagonizes MPTPinduced neurotoxicity to the dopaminergic neurons in mouse substantia nigra. Exp Neurol 2008; 212:532-537.

42 Breuer W, Epsztejn S, Cabantchik ZI. Iron acquired from transferrin by $\mathrm{K} 562$ cells is delivered into a cytoplasmic pool of chelatable iron(II). J Biol Chem 1995; 270:24209-24215.

43 May JM, Qu ZC, Mendiratta S. Role of ascorbic acid in transferrin-independent reduction and uptake of iron by U-937 cells. Biochem Pharmacol 1999; 57:1275-1282.

44 Wetli HA, Buckett PD, Wessling-Resnick M. Small-molecule screening identifies the selanazal drug ebselen as a potent inhibitor of DMT1-mediated iron uptake. Chem Biol 2006; 13:965-972.

45 Armeni T, Damiani E, Battino M, Greci L, Principato G. Lack of in vitro protection by a common sunscreen ingredient on UVA-induced cytotoxicity in keratinocytes. Toxicology 2004; 203:165-178.

46 Xue L, Zhou B, Liu X, et al. Structurally dependent redox property of ribonucleotide reductase subunit p53R2. Cancer Res 2006; 66:1900-1905. 